\title{
The Box Tree Moth: An Invasive Species Severely Threatening Buxus Natural Formation in NW Italy
}

\author{
Chiara Ferracini ${ }^{1, *} \mathbb{\oplus}$, Cristina Pogolotti ${ }^{1}$, Paolo Mancardi ${ }^{1}$, Michela Miglio ${ }^{1}\left(\right.$, Simona Bonelli ${ }^{2}$ and \\ Francesca Barbero 2 (D) \\ 1 Department of Agricultural, Forest and Food Sciences (DISAFA), University of Torino, Largo Paolo Braccini 2, \\ 10095 Grugliasco, Italy; cristina.pogolotti@unito.it (C.P.); paolo.mancardi@unito.it (P.M.); \\ michela.miglio@unito.it (M.M.) \\ 2 Department of Life Sciences and Systems Biology, University of Torino, Via Accademia Albertina 13, \\ 10123 Torino, Italy; simona.bonelli@unito.it (S.B.); francesca.barbero@unito.it (F.B.) \\ * Correspondence: chiara.ferracini@unito.it; Tel.: +39-01-1670-8700
}

check for updates

Citation: Ferracini, C.; Pogolotti, C.; Mancardi, P.; Miglio, M.; Bonelli, S.; Barbero, F. The Box Tree Moth: An Invasive Species Severely

Threatening Buxus Natural Formation in NW Italy. Forests 2022, 13, 178. https://doi.org/10.3390/ f13020178

Academic Editor: Marina

J. Orlova-Bienkowskaja

Received: 23 December 2021

Accepted: 20 January 2022

Published: 24 January 2022

Publisher's Note: MDPI stays neutral with regard to jurisdictional claims in published maps and institutional affiliations.

Copyright: (c) 2022 by the authors. Licensee MDPI, Basel, Switzerland. This article is an open access article distributed under the terms and conditions of the Creative Commons Attribution (CC BY) license (https:/ / creativecommons.org/licenses/by/ $4.0 /)$.

\begin{abstract}
The box tree moth (BTM), Cydalima perspectalis Walker, represents one of the recent examples of exotic insect pests native to Asia accidentally introduced in Europe by the nursery trade. In Europe, BTM develops on Buxus sempervirens L., causing significant damage to ornamental and natural plants. (2) Basic aspects of BTM biology were investigated at three sites in the NW Alps, where B. sempervirens occurs on rocky slopes, forming a protected habitat. In 2019-2021, we evaluated: (i) the seasonal flight activity with sex pheromone traps, (ii) the fecundity and the effects of food on the egg load, (iii) the potential adaptation of BTM on native secondary host plants, and (iv) the recruitment of natural enemies. (3) Our results revealed the presence of two generations per year. The number of mature eggs increased in fed adults and was higher in females of the first generation. No evidence of BTM shift on secondary plants was found in either laboratory or natural conditions, and no significant occurrence of natural enemies was recorded, except for one pupa of the tachinid Pseudoperichaeta nigrolineata. (4) Our findings provide valuable information to address and timely plan management strategies to preserve $B$. sempervirens as an essential component of rare forest ecosystems.
\end{abstract}

Keywords: Cydalima perspectalis; Buxus sempervirens; invasive alien species; forest insect pest; Habitat 5110; conservation status

\section{Introduction}

The box tree moth (BTM), Cydalima perspectalis Walker (Lepidoptera: Crambidae), is a pest species common in China, Korea, and Japan. Due to the nursery trade of its host plants, in the last decade, BTM has spread from its native East Asian area across the Palearctic realm, reaching Canada in the Nearctic region in 2018 [1]. After being reported in Germany and The Netherlands in 2006, BTM invaded most of Europe (Switzerland, France, England, Austria, Belgium, Croatia, Czech Republic, Hungary, Romania, Slovenia, Slovakia) and Turkey, reaching almost all central and southern European countries [2,3]. This species was found for the first time in Italy in 2010, quickly invading most of the Italian regions [2,4-6], including Piedmont (NW Italy) in 2013 [7]. BTM is a multivoltine species in its native range, being able to perform up to five generations per year depending on the climatic conditions [8]. In northern and central European countries, BTM is bivoltine, with two generations per year occurring in June and late August [9]; in southern Europe and the Caucasus, three generations can occur [3].

In its native range, the species feeds mainly on the Japanese and Chinese box tree (Buxus microphylla Siebold et Zucc., Buxus sinica Rehder et Wilson) [8,10], but it was also reported on Euonymus japonicus Thunberg, Euonymus alatus Siebold (Celastraceae), Ilex purpurea Hasskarl (Aquifoliaceae), Murraya paniculata L., and Pachysandra terminalis Siebold 
et Zucc. (Rutaceae) [3,11-13]. In the area of introduction, it develops mainly on B. sempervirens. Box trees enter as either a typical or a differential species of several forest and semiforest associations and in Europe are patchily distributed from Portugal to Austria and from Greece to the UK, extending from the sea level up to $2000 \mathrm{~m}$ [14].

Moreover, $B$. sempervirens is typically used for hedges, borders, and plant sculptures as ornamental plants. It is present in the urban environment, in cemeteries, and in typical Italian gardens and traditionally used for its ecological plasticity and great adaptability [14]. Box trees are also found in beech wood and on Alpine rocky slopes form the Habitat 5110 "Stable xero-thermophilous formations with Buxus sempervirens on rock slopes (Berberidion p.p.)" according to the $92 / 43 / \mathrm{EEC}$ Habitats Directive. This latter is a quite common habitat in southern France [14,15] and in NW Italy [6]. According to the Natura 2000 European Database, Habitat 5110 is known for 310 European Natura 2000 sites (SCIs, SPAs, and SACs) distributed across 9 countries: France (146 sites), Spain (109), Italy (33), Belgium (12), Germany (3), Greece (3), Portugal (2), Luxembourg (1), and the UK (1). In particular, in various Italian regions (Piedmont, Liguria, Trentino-Alto Adige, Tuscany, Umbria, Marche, Latium, Abruzzo, and Basilicata regions), several Natura 2000 sites including Habitat 5110 are present. All these sites have been designated as Sites of Community Importance (SCIs) and Special Areas of Conservation (SACs), being subjected to conservation measures, especially since the EU biogeographical conservation status has been assessed as being unfavorable or bad in all the Alpine regions and is getting worse also in relation to invasion by BTM [16]. The occurrence in urban environments has favored and still favors its expansion, creating comfortable ecological corridors and posing a severe threat in natural sites.

The damage caused by BTM is due to the trophic activity of the larvae feeding on leaves and shoots and severely harming host plants. Infested plants typically show large amounts of silk threads with frass. In high population density, larvae can feed on the bark and lead to complete defoliation, posing a great threat to the host plants [9]. For the above reason, the species was initially included as a pest in the Alert List of the European Plant Protection Organisation (EPPO) in 2007 but was removed in 2011 because the EPPO member countries requested no particular action [2]. In a few years, a large amount of native box trees has been lost in Europe due to this invasive moth. BTM has devastated large areas of native box communities in the region of Basel (Switzerland), in the Russian Caucasus, in the French Massif Central and the Pyrenees, in the Grenzach-Wyhlen Nature Reserve (Germany), and in the eastern Black Sea region [3,15]. Projections on the future BTM distribution based on bioclimatic models envisage the expansion of the species across the whole European continent apart from the northern territories (roughly from Finland latitude upwards) and suggest a higher negative impact in southern areas where multiple generations occur [9].

In addition, due to its high spread abilities and low or null competition or control by other biotic components of the ecosystem, the BTM impact is particularly significant when the pest extends to naturally occurring Buxus formations [9], which represent unique habitat types in Europe. Therefore, in the present work, we aimed to gather essential information on the biology of the species occurring in natural boxwood to implement appropriate control strategies. A 3-year study was carried out in NW Italy to investigate (i) the seasonal flight activity of the BTM with sex pheromone traps, (ii) the egg load of BTM females under laboratory conditions to evaluate fecundity and the effects of food (honey fed vs. unfed females) on the egg load, (iii) the potential adaptation of BTM on native secondary host plants, and (iv) the presence of natural enemies.

Knowledge about the phenology, fecundity, occurrence on new hosts of BTM's newly established populations, and recruitment of native natural enemies is pivotal to timely and effectively control the pest impact and expansion. 


\section{Materials and Methods}

\subsection{Survey Sites}

Investigations were performed in a 3-year period (2019-2021) in the Piedmont region (NW Italy) in the Vermenagna valley (Vernante site; $44^{\circ} 14^{\prime} 13.1^{\prime \prime} \mathrm{N}, 07^{\circ} 32^{\prime} 36.3^{\prime \prime} \mathrm{E} ; 857 \mathrm{~m}$ a.s.1.), in the Grana valley in the "Comba di Castelmagno" Site of Community Importance (SCI) (IT1160065) (Pradleves site; $44^{\circ} 24^{\prime} 44.6^{\prime \prime} \mathrm{N}, 07^{\circ} 16^{\prime} 16.3^{\prime \prime} \mathrm{E} ; 813 \mathrm{~m}$ a.s.l.), and in the Tanaro valley (Garessio site; $44^{\circ} 10^{\prime} 33.7^{\prime \prime} \mathrm{N}, 07^{\circ} 59^{\prime} 10.1^{\prime \prime} \mathrm{E} ; 450 \mathrm{~m}$ a.s.1.), near the "Monte Antoroto" SCI (IT1160035).

Both the Vernante and Garessio sites are typical forest areas, characterized by various woody broadleaf species (oak, hophornbeam, wild cherries, maple, ash, and European spindle tree) mixed with $B$. sempervirens shrubs. Conversely, the Pradleves site is characterized by stable xerothermophilous and calcicolous shrubs dominated by B. sempervirens of montane level (according to EU Habitat 5110). These formations correspond to xerothermophilous Buxus thickets with their fringe associations of the Geranium sanguineum L. on a calcareous or siliceous substratum. The characteristic plants are B. sempervirens, blackthorn, cornel, hophornbeam, barberry, and common privet. The three study sites were about 5 ha each. Vernante was about $30 \mathrm{~km}$ away from Pradleves and $40 \mathrm{~km}$ from Garessio, the latter two being $60 \mathrm{~km}$ apart. All information concerning the three surveyed sites is given in Supplementary Table S1.

\subsection{Seasonal Flight Activity}

The BTM adult population dynamics were investigated using sexual pheromone lures by Novapher s.a.s. ((Z)-11-hexadecenal (Z11-16:Ald) $(80 \%)+($ E)-11-hexadecenal (E1116:Ald) (20\%)). In 2019-2021, three sticky traps (Delta Trap ${ }^{\circledR}$, Biogard, Grassobbio (BG), Italy) per site were used, about $30 \mathrm{~m}$ away from each other. To test the effectiveness of different trap types, funnel traps (three traps per site; Mass Large ${ }^{\circledR}$, Isagro S.p.A, Novara, Italy) were also placed at the three sites in 2020-2021. Traps were hung on the branches of broadleaved trees at $2 \mathrm{~m}$ in height, on the outer surface of the tree canopy, and closer to infested box trees (less than $2 \mathrm{~m}$ ). Pheromone lures were replaced every 4 weeks according to the manufacturer's recommendations, whereas traps were inspected weekly from June to October until no adult was recorded for 3 consecutive weeks. At each inspection, the sticky surface of the trap was removed and replaced with a new one, and funnel traps were emptied, moving the captured moths in a plastic bag. All the sticky surfaces removed and adult moths caught in the funnel traps were taken to the laboratory to be counted and identified. All other insects different from C. perspectalis moths were discarded.

During the species flight peak, three funnel traps placed in Pradleves and three located in Vernante were inspected at 6:00 a.m., 6:00 p.m., and 10:00 p.m. for 3 consecutive days to evaluate whether adults are active during the day, dusk, or night.

Moreover, to determine at which stage of the life cycle our BTM populations overwinter, 30 larvae were randomly collected in their cocoons in the 3 surveyed sites in December 2019, for a total of 90 individuals. Infested plants were visually inspected, and larvae were manually taken, being careful not to damage them. All individuals were taken to the entomology laboratory of DISAFA, and their head capsule width was measured under a stereomicroscope at $25 \times$ magnification to assess their larval instar stage according to Nacambo et al. [9].

\subsection{Insect Culture}

Different instars of BTM were collected manually in infested boxwood located at the surveyed sites during autumn 2018 and reared under laboratory conditions at the entomology laboratory of DISAFA $\left(24 \pm 1{ }^{\circ} \mathrm{C}, 60 \% \pm 5 \% \mathrm{RH}\right.$, photoperiod of 16:8 (L:D) $\left.\mathrm{h}\right)$ until adult emergence. Larvae were fed on watered box tree twigs (B. sempervirens, $30 \mathrm{~cm}$ in length) in cages $(1 \times 1 \times 1 \mathrm{~m})$ having a stainless steel frame structure supporting a plastic insect-proof net (mesh $0.23 \times 0.23 \mathrm{~mm}$ ). Fresh box tree twigs were provided twice a week. The newly emerged adults were transferred to a cage (as described above), where food was 
supplied as a diluted $(10 \%)$ honey solution on a small piece of cotton placed on a slide in the middle of the cage [9]. Healthy B. sempervirens twigs were provided ad libitum to allow oviposition, thus enabling a continuous mass rearing.

\subsection{Female Fecundity}

To assess the female fecundity, pupae were placed in a separate rearing cage (as described above) until adult emergence. A total of 50 freshly emerged females were sorted into 5 cages, each ultimately containing 10 individuals, to generate 3 age cohorts $(<4,48,96 \mathrm{~h})$. Ten newly emerged females were killed with ethyl acetate within $4 \mathrm{~h}$ from emergence. Of the remaining 40 adults, half were fed with a honey solution (as described above) and killed after $48(n=10)$ or $96 \mathrm{~h}(n=10)$. Their fecundity was compared with that of a control, consisting of same-age ( 48 or $96 \mathrm{~h}$ ) individuals starved until they were killed. The same protocol was adopted using pupae of the second generation collected in August in the same sites. The cages were maintained in a climatic chamber under controlled conditions $\left(24 \pm 1{ }^{\circ} \mathrm{C}, 60 \% \pm 5 \% \mathrm{RH}\right.$, photoperiod of $16: 8$ (L:D) h).

The specimens were placed on a microscope slide $(25 \times 75 \times 1 \mathrm{~mm})$ into a phosphatebuffered saline (PBS) solution for ovary dissection. Egg load was assessed by dissecting each female under a stereomicroscope at $25 \times$ magnification. The abdomen was separated from the rest of the body using a couple of needles. Ovaries were gently removed from the abdomen by means of micropin needles and spread on a slide for egg load counts, according to the method described by Picciau et al. [17,18]. Bigger and well-formed eggs with a smooth surface were categorized as mature eggs (Supplementary Figure S1). The number of mature eggs was counted under a microscope at $115 \times$ magnification.

Ovigeny strategy was determined on 10 females following the criteria described by Jervis et al. [19]. The ovigeny index was calculated by dividing the initial mean load of mature egg by the maximum average lifetime fecundity.

\subsection{Evaluation of the Adaptation on Secondary Host Plants}

Food plant preference was investigated by selecting native plants occurring near infested box trees in the surveyed sites belonging to genera reported in the literature as secondary hosts in the area of origin [3]. The selected plants were the European spindle tree, Euonymus europaeus L., and the English holly, Ilex aquifolium L. The potential host range of the pest was investigated by conducting both no-choice and multichoice tests on the selected plants in controlled conditions. Moreover, during all the surveys the monitoring of the potential damage by BTM was evaluated by visual inspections of the selected secondary host plants in field conditions. In the no-choice experiments, fresh leaves of E. europaeus collected in the surveyed sites were placed in a $9 \mathrm{~cm}$ diameter Petri dish lined with moist filter paper. Five first-instar larvae were placed at the center of the Petri dish and then kept in a climatic chamber $\left(24 \pm 1{ }^{\circ} \mathrm{C}, 60 \% \pm 5 \% \mathrm{RH}\right.$, photoperiod of 16:8 (L:D) h). The same protocol was followed using I. aquifolium leaves and the primary host $B$. sempervirens. Ten replicates were conducted for each plant species, resulting in 150 larvae tested. In the multichoice experiments, 5 first-instar larvae were placed in a Petri dish lined with moist filter paper and containing fresh leaves of E. europaeus, I. aquifolium, and B. sempervirens. Ten replicates were conducted for each plant species, resulting in 50 larvae tested. In both no-choice and multichoice experiments, host plants were taken in the first 10 days of July, and leaf areas were roughly equivalent among plants. Plant stems were inserted in an Eppendorf tube $(2.5 \mathrm{~mL})$ containing water to maintain leaf turgor. Larvae were allowed to feed for $48 \mathrm{~h}$, and all the Petri dishes were checked twice a day to detect larval feeding damage. The same protocol was adopted using third-instar larvae collected from mass rearings.

\subsection{Potential Adaptation of Natural Enemies}

During field monitoring, visual observations were carried out on the box tree plants to assess the presence of natural enemies (unhealthy larvae and pupae, presence of egg, larval, 
and/or pupal parasitoids). A sample of $180 \mathrm{egg}$ clusters (10 clusters per generation per site per year; each cluster consisted of 10-15 eggs) was collected and taken to the DISAFA laboratory. Each egg cluster was individually kept in Petri dishes (diameter of $90 \mathrm{~mm}$ ), lined with wet filter paper. Eggs were checked 3 times a week until eclosion to detect potential egg parasitoids. Moreover, a sample of 540 larvae (30 larvae per generation per site per year) was randomly collected in 3 periods (April, July, September) on natural box tree stands. Caterpillars were provided with healthy box tree plants and maintained in cages $(1 \times 1 \times 1 \mathrm{~m})$ having a stainless steel frame structure supporting a plastic insect-proof net (mesh $0.23 \times 0.23 \mathrm{~mm}$ ). Plants were watered regularly to prevent desiccation, and larvae were checked 3 times a week until pupation to detect potential BTM's parasitoids.

\subsection{Statistical Analyses}

All data were first tested for homogeneity of variance (Levene's test) and log-transformed to stabilize variances and normalize the data. The number of males captured in pheromonebaited traps (sticky vs. funnel traps) and the egg load were compared with $t$-test independent samples $(p<0.05)$, followed by Tukey's test for multiple comparisons. Averages are expressed as mean values \pm standard errors unless otherwise stated. All analyses were performed using SPSS version 22.0 (SPSS, Chicago, IL, USA)

\section{Results and Discussion}

\subsection{Seasonal Flight Activity}

The seasonal flight activity, reported as the total number of male moths captured by pheromone-baited sticky traps in 2019-2021, is given in Figure 1A-C. Two main flight periods were identified annually, highlighting two clearly separated generations per year with two peaks. In detail, the peak of the first generation was always observed between 10 and 20 July for all sites and years. A second generation occurred in mid-August, with a peak in late August-early September. No male was ever captured after the beginning of October. Although BTM was reported to perform three generations per year in centraleastern Europe and some locations in northern Italy [20-22], the life cycle monitored in the 3-year period confirms a phenology pattern similar to that in other Asian and European countries [9,23-26]. However, in contrast to Göttig and Herz [25], who found the major adult flight occurring during the second flight phase in early September, the highest number of flying individuals was detected in midsummer during the first generation.

BTM populations displayed a similar trend in temporal patterns in the different surveyed sites and years. The flight activity started in mid-June; then the rate of captures in pheromone traps increased and reached a peak in mid- to late July. The maximum numbers of individuals caught were 45, 38, and 15 males in Pradleves and 22, 28, and 21 at Vernante in 2019, 2020, and 2021, respectively. In Garessio, the traps captured a substantial number of individuals, with a maximum of 25 males, only in 2019. Due to the high infestation level of the previous year, most of the plants in Garessio were utterly defoliated, corresponding to the third level on the damage scale by Raineri et al. [6]. In 2019, BTM larvae continued eating the box trees voraciously, leaving no chance for the plants to recover. During periodic monitoring in Garessio, a few plants were found to produce young sprouts, but most of them were wholly defoliated and largely decorticated by mature larvae, causing the plants to dry out and almost completely die. Consequently, due to heavy damage, in 2020, traps recorded no adult moths, and only one adult was trap-collected in 2021. Significant defoliation, repeatedly across a growing season or over several years, is likely to weaken plants and lead to plant death, with no chance to recover. These observations are in line with those of Badano et al. [27], reporting a deep BTM population crash in case of limited food resources in Liguria, a region close to Garessio. Conversely, in the Pradleves and Vernante sites, as the presence of BTM was reported later and for the higher altitude with respect to Garessio, the plants were still able to recover even after severe infestations. 

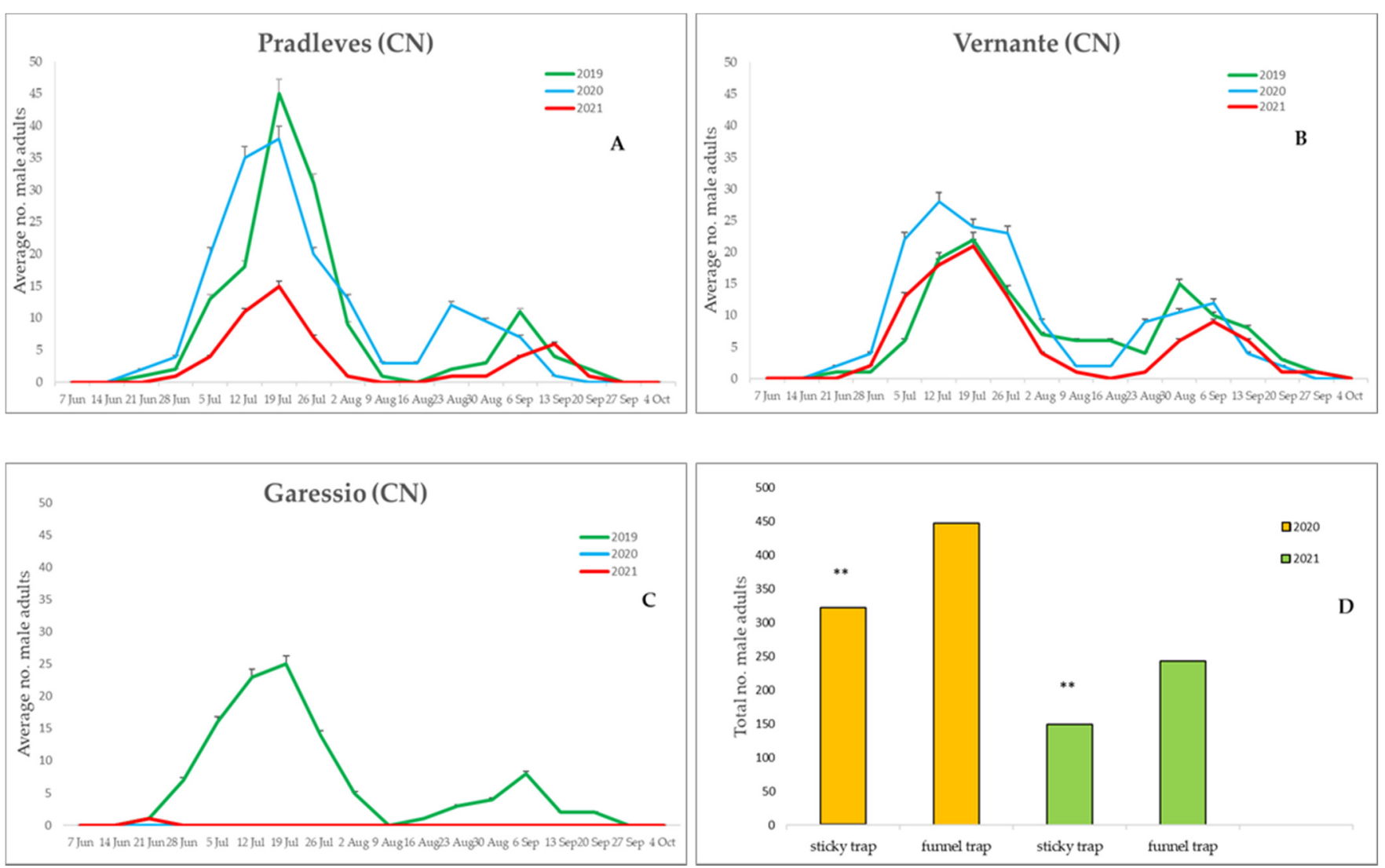

Figure 1. Seasonal flight activity of Cydalima perspectalis Walker recorded in Pradleves (A), Vernante (B), and Garessio (C) collected with pheromone-baited sticky traps in comparison with pheromonebaited funnel traps (D). Green line refers to 2019, blue line to 2020, and red line to 2021. Histograms refer to the comparison between sticky and funnel traps (yellow: 2020; green: 2021). The asterisks indicate significant difference $(* *, p<0.01)$ between bars, according to the paired $t$-test.

In Italy, the impact of BTM was assessed only for the Liguria region (NW Italy), where more than $50 \%$ of the Buxus formation was reported as completely destroyed in less than 5 years [6,27]. Most of this spread is the result of natural dispersal, but also new populations occurred farther away, probably facilitated by human transport of infested box trees. Data from Germany indicate that natural dispersal is about $5-10 \mathrm{~km}$ per year [11], but recent models estimate a spread rate of BTM in Europe of up to $155 \mathrm{~km} /$ year [28]. Observations on its dispersal in Piedmont since 2016 are consistent with the German data. Well-established BTM populations have been found alongside natural Buxus formations, confirming earlier observations in 2016-2018 in the same areas surveyed in 2019-2021. Moreover, outbreaks in nurseries, cemeteries, historical monuments, public parks, and private gardens have been observed on ornamental box trees ( $\mathrm{CF}$ and $\mathrm{FB}$, personal observations).

This study helped identify the most suitable trap in catching BTMs, comparing funnel vs. sticky traps. In the literature, there are in fact numerous examples pointing out how trap design affects catches of moths using pheromone lures, and specifically several investigations highlighted how their shape and placement might affect captures [29,30]. When compared with sticky traps, the funnel traps captured a significantly higher (more than 30\%) number of BTM males (Figure 1D), both in 2020 and 2021 ( $t$-test $=-3.462, n=72$; $\mathrm{df}=1 ; p=0.0046$ in 2020 and $t$-test $=-5.410, n=72 ; \mathrm{df}=1 ; p=0.0027$ in 2021). In total, 447 and 243 males were collected from funnel traps vs. 321 and 149 from sticky traps in 2020 and 2021, respectively. Funnel traps were found to be more suitable for monitoring flight activity and proved to be the most accurate and effective monitoring system available on the market to measure BTM population levels. However, although monitoring traps could be useful for proper timing of control strategies [20,31,32], in all sites and years the number 
of male adults trapped was negligible when compared with the high level of infestation in boxwood, thus questioning whether pheromone-baited traps truly reflect moth phenology, as already pointed out for other insect pests in agriculture [33,34]. Recently, Molnár and colleagues [35] tested the attractiveness of phenylacetaldehyde, eugenol, and methyl salicylate blends to both BTM males and females. Their results showed a high potential for these compounds to lure both sexes into traps, eventually becoming an effective control method.

The most frequent adult morphotype caught in the traps was the typical white with a dark brown margin form, while the melanic type accounted for less than $10 \%$ of all specimens collected. Moreover, the in-depth inspection of a trap subset performed at subsequent timing revealed that all the 179 BTMs were captured between 10:00 p.m. and 6:00 a.m., while no moths were found between 6:00 a.m. and 6:00 p.m. or at dusk (6:00-10:00 p.m.). Even if some authors refer to BTM as a crepuscular/nocturnal moth (e.g., [22]), our investigations highlighted how this pest has a strictly nocturnal behavior, as adults were trapped in a specific time window between 10:00 p.m. and 6:00 a.m.

In the surveyed sites, we observed overwintering larvae starting from the end of October/beginning of November. In contrast to Badano et al. [27], who reported the presence of cocoons on other plant hosts (e.g., Fraxinus, Pinus, Juniperus), in our surveyed sites overwintering larvae were detected only on $B$. sempervirens, even in case of extensive defoliated plants.

The average head capsule width of overwintering larvae collected in the field was $0.98 \pm 0.02 \mathrm{~mm}$, corresponding to the third instar according to the scale by Nacambo et al. [9]. This measurement showed that the caterpillars mainly overwinter as third-instar larvae. However, there is a lively debate in the literature about the BTM overwintering stage. In China, most larvae overwinter as second- to fourth-instar larvae, and in Japan at the fourth or fifth instar [9]. In Europe, developmental investigations suggest that larvae overwinter mainly in their third instar $[9,21]$, even if Badano et al. [27] confirmed that the first-instar larva is the overwintering stage of the box tree moth in the Liguria region (very close to our investigation area). Studying larvae in both controlled and natural conditions, Poitou and colleagues [36] found broad plasticity in overwintering stages, which can potentially survive and overwinter at almost all instars (from the second to the fifth). Besides temperatures, the photoperiod is one of the main drivers inducing insect diapause [37]. Some indications about day lengths required by BTM for overwintering are known (13:30 h in Europe [9] and between 12:50 and 13:36 h in China [38]). Therefore, differences in photoperiod thresholds and temperatures could drive variation in these life-history traits across BTM distribution. However, microclimate conditions that strongly vary along geographical gradients and are known to affect insect biology could also play a role in shaping differences in overwintering stages (e.g., $[39,40])$. Factors affecting the duration are even less understood [28], but could be related to temperature [36].

The suitability of climatic factors as modelled by Climex [9], and the occurrence of food plants, will significantly influence BTM's presence and spread in the next few years. In addition, Suppo and colleagues [28] warned about the potential effect of climate change, which can boost the expansion of BTM, also allowing the production of more generations (up to four) thanks to an increase of two degrees in temperature.

In Europe, several chemical insecticides are authorized on ornamental Buxus plants, but their use is often prohibited in the forestry environment and limited to nurseries. Other control strategies have been investigated in laboratory conditions so far (larval suitability to native parasitoids, oviposition-deterring effect by essential oils, larval susceptibility to baculovirus), but their role needs to be confirmed under field conditions [41-46]. Aerial treatments with bioinsecticides based on the bacterium Bacillus thuringiensis var. kurstaki (Btk) have been tested on BTM young larval instars with controversial results [6,8]. Btk effectiveness can be limited by the coverage level and the lack of access for vehicle-mounted spraying. However, even if treatments do not prevent recolonization of treated areas, they 
may be considered an effective temporary solution to protect small box clumps and/or high-value natural stands [8].

The disappearance of large areas of boxwood forests will affect the whole ecosystem in these regions. The defoliation of box trees has been related to changes in the ground-covering vegetation, thus increasing the exposure to sunlight and impacting the related biodiversity, as already observed in the Nature Reserve of Grenzach-Wyhlen in Germany [47] and in the Jura Mountains [48]. Moreover, since box trees have a slow rate of growth, it is predictable that co-occurring tree species having faster growth rates would replace them, permanently altering the traits of the woodland ecosystem. With this regard, in NW Italy, Habitat 5110 can host endemisms of calcareous cliffs, peculiar alpine assemblages, and highly diverse communities of pollinators that could be at risk.

\subsection{Female Fecundity}

The results presented in this research showed that the egg load was strongly $<1$ in early females with the ovigeny index calculated to be 0.0677 , indicating an extremely synovigenic behavior. Newly emerged specimens ( $<4 \mathrm{~h}$ age category) of the first generation almost lacked mature eggs; these females $(n=10)$ bore an average of $6.10 \pm 1.73$ eggs. In the following days, the number of mature eggs increased rapidly, also depending on food availability (Figure 2A). The average egg number in $48 \mathrm{~h}$ age adults was lower $(73.45 \pm 6.82)$ in starved females than in fed individuals $(95.1 \pm 12.46)(t$-test $=-5.007$; $\mathrm{df}=1 ; p<0.01)$. After 4 days from their emergence ( $96 \mathrm{~h}$ age category), starved females had a lower $(91.9 \pm 8.63)$ egg load than fed females $(160.9 \pm 13.44)(t$-test $=-9.147 ; \mathrm{df}=1$; $p<0.001)$.

For each age cohort, the mean number of mature eggs carried by second-generation females was lower than the egg load recorded for the first generation $(<4 \mathrm{~h}$ : $t$-test $=-1.041$, $\mathrm{df}=3.305, p=0.210 ; 48 \mathrm{~h}: t$-test $=-4.077, \mathrm{df}=5.069, p=0.004 ; 96 \mathrm{~h}: t$-test $=-0.470$, $\mathrm{df}=1.010, p=0.032$ ) (Figure 2). Second-generation specimens that emerged for less than $4 \mathrm{~h}$ had an average of $5.7 \pm 0.90$ mature eggs. Dissection revealed that the number of mature eggs significantly differed between females allowed to feed and starved adults (Figure 2B; mean number of mature eggs for $48 \mathrm{~h}$ females; $65.6 \pm 9.7 \mathrm{vs} .27 .7 \pm 3.41$; $t$-test $=-5.007$; $\mathrm{df}=1 ; p<0.001$; mean number of mature eggs for $96 \mathrm{~h}$ females; $103.4 \pm 17.75$ vs. $68.3 \pm 13.9$; $t$-test $=-9.110 ; \mathrm{df}=1 ; p<0.001)$. Our findings are consistent with those reported by Wan et al. [8] for the BTM area of origin, revealing a variation in the average lifetime fecundity per female between generations. Nevertheless, our counts are lower than the egg loads found by Wan et al. [8], which range from $482.5 \pm 213.2$ eggs for the overwintered generation to $199.4 \pm 107.6$ for the third generation. This comparison suggests that BTM fecundity is higher in its native distribution. Differences in the invasive populations could be explained as the outcome of genetic drifts, such as founder effects and bottlenecks [49].

In addition to the overwintering stage (discussed above), other life-history traits, such as mean development time, the number of generations per year, and fecundity, show phenotypic plasticity and could be selected by biotic and abiotic factors, mostly associated with the length of the frost-free period or mean summer temperatures. Populations with more extended frost-free periods are predicted to have shorter development times and a greater number of generations per year, while the egg load is expected to decrease if average temperatures grow (e.g., [50]). However, further comparisons between climatic and environmental conditions of native and invasive areas are needed to shed light on the differences we found in the BTM fecundity, overwintering, and flight activity in the Italian Alps with respect to Asian populations. The prompt evolution of plasticity could be a key factor for the success of invasive species, but due to the complexity of this phenomenon, it has been rarely surveyed empirically, and the majority of experiments have been performed using plants [50,51]; but see [52,53]. Increase of knowledge in BTM ecological requirements, general biology, and genetic variation would pave the way for improving modeling based on climatic and environmental projections, which eventually serve as crucial tools for controlling BTM expansion. 


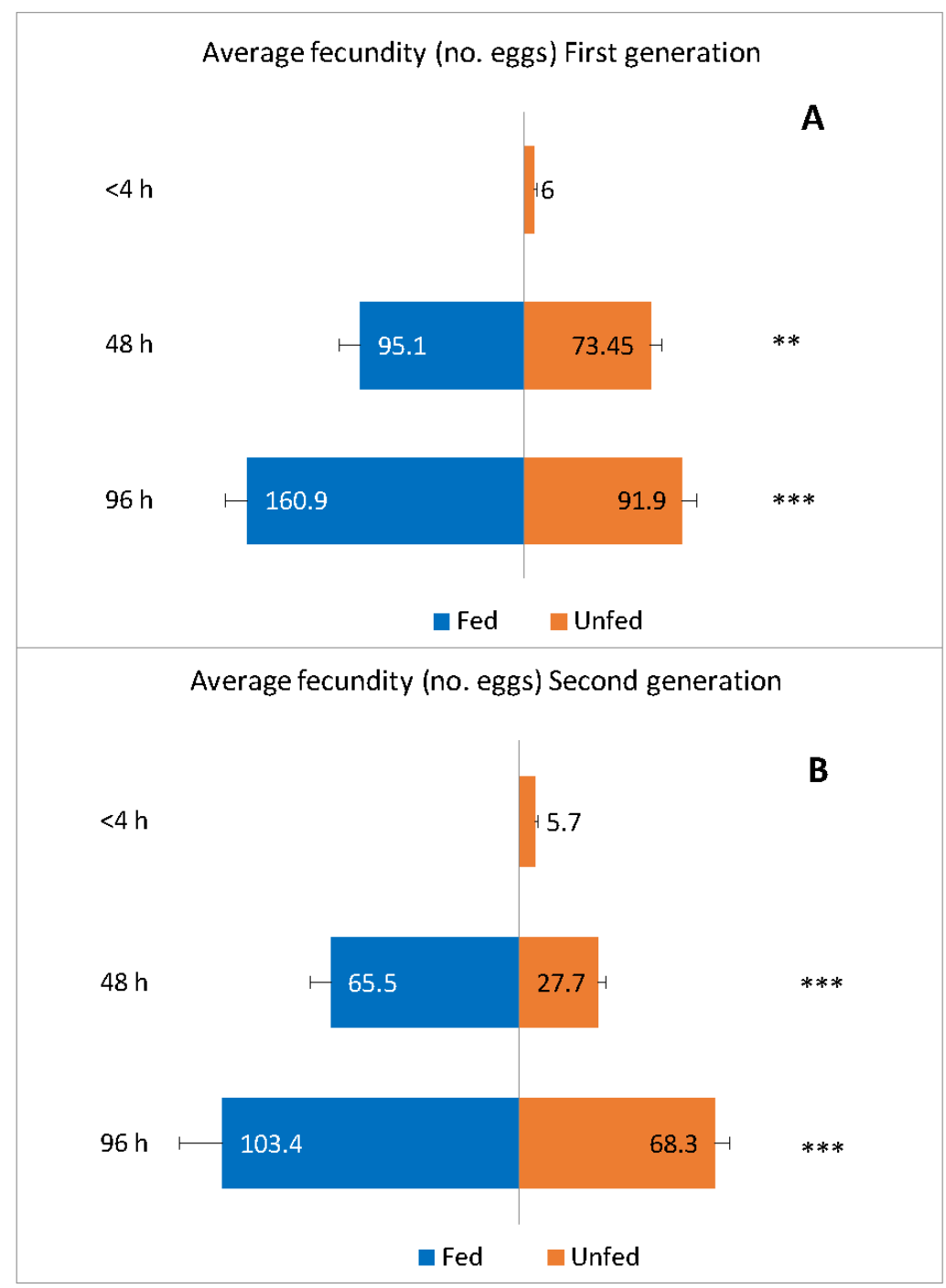

Figure 2. Mean number ( $\pm \mathrm{SE})$ of mature eggs in Cydalima perspectalis according to age cohort $(<4,48$, $96 \mathrm{~h}$ ), availability of food (red bar = unfed females; blue bar = honey-fed females), and generation ( $\mathbf{A}=$ first generation; $\mathbf{B}=$ second generation). Line bars represent standard error of the mean. Sample size for each age cohort $=10$. The asterisks indicate significant difference $(* *, p<0.01 ; * * *, p<0.001)$ between bars, according to the paired $t$-test.

\subsection{Evaluation of the Adaptation on Secondary Host Plants}

Our observations highlighted that only Buxus sp. resulted in being affected, with no damage recorded on secondary native host plants (Euonymus sp. and Ilex sp.) in both controlled and field conditions. Several cases in which insect pests have broadened their feeding niche to native and/or exotic, and successfully increased their host range and distribution area, are well documented [54-56].

In our work, under no-choice conditions in which only one plant species was available for larvae, they fed only on B. sempervirens. No larval development was recorded on the other plants, on which both first- and third-instar larvae starved to death (Figure 3A,B). Similarly, in the multichoice experiments where larvae were simultaneously offered with B. sempervirens, E. europaeus, and I. aquifolium leaves, the trophic activity was recorded only on the box tree. In field conditions, over 50 plants for each secondary host co-occurring with B. sempervirens were inspected, and no damage was ever recorded (Figure 3C). The signs of BTM presence reported by Badano et al. [27] on Fraxinus ornus L., Pinus nigra Arnold, and Juniperus communis L. cannot be ascribed to host shifts, as these plants are used only as shelters for pupation. 

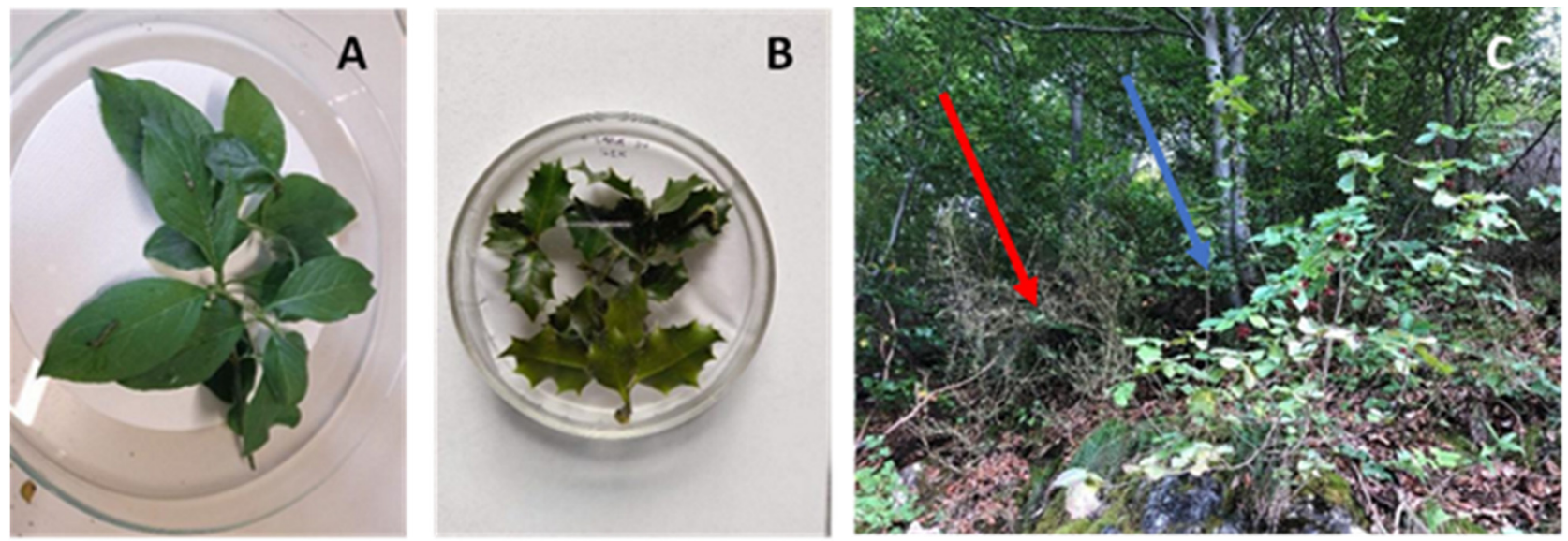

Figure 3. No-choice tests on Euonymus europaeus (A) and Ilex aquifolium (B) in controlled conditions and presence of healthy E. europaeus (blue arrow) located near Buxus sempervirens severely infested by Cydalima perspectalis (red arrow) in field conditions (C).

On the other hand, BTM represented the main threat to boxwood, while other phytosanitary threats such as the boxwood blight caused by the fungus Cylindrocladium buxicola Henricot and the box sucker Psylla buxi L. (Hemiptera: Psyllidae) were only occasionally detected in the study areas.

\subsection{Evaluation of the Adaption of Natural Enemies}

The natural enemy complex in the investigated area was very poor. No significant occurrence of natural enemies was recorded in field conditions, except for one pupa of Pseudoperichaeta nigrolineata Walker (Diptera: Tachinidae) observed in 2019 in the Pradleves site. The larval parasitism recorded was in line with previous observations by Nacambo [57] in northwestern Switzerland, highlighting how the adaptation on BTM populations was occasional $(<1 \%)$ and mostly unknown. This evidence contributed to demonstrating that this invasive pest is not yet regulated by natural enemies $[8,9,57,58]$. Even predators have never been found; alkaloids accumulated in the larval body may in fact promote self-defense against natural enemies [10]. The suitability of native biocontrol agents has been investigated in laboratory conditions to assess their potential role in conservative biocontrol programs $[41,42,59,60]$, but until now, no promising candidate for biocontrol has been selected for classical or conservative biocontrol programs.

\section{Conclusions}

1. Our results suggest that life-cycle traits, such as phenology and fertility, differ in the invasive populations compared with the native ones. Such differences emerge from complex climatic, genetic, and evolutionary patterns (as discussed above) and could give rise to geographic biotypes showing different developmental responses.

2. Robust data on the BTM seasonal flight activity, effectiveness of different pheromonebaited traps, and female fecundity will be crucial to timely planning management strategies to preserve box trees, as essential components of several rare forest ecosystems. Since most of these Buxus natural formations are designated as SCIs and SACs and form critically important ecological habitats, control protocols should be effective against BTM, but have to consider the potential impact of treatments on organisms providing ecosystem services, primarily pollinators and BTM's natural enemies.

3. Hence, novel approaches to control C. perspectalis are urgently needed to minimize the loss of ornamental and native box trees across Europe. Preventing further infestation outbreaks is crucial to preserve relict species, such as Buxus balearica, occurring in southern Spain, Balearic Islands, and Sardinia, and B. colchica Pojark in the Caucasus. 


\begin{abstract}
Supplementary Materials: The following supporting information can be downloaded at: https: / / www.mdpi.com/article/10.3390/f13020178/s1, Table S1: Sampling sites monitored in the 3-year period of 2019-2021. Figure S1: Egg load assessed by dissecting the abdomen of a female Cydalima perspectalis Walker. The number of mature eggs was counted under a microscope at $115 \times$ magnification. Bigger and well-formed eggs with a smooth surface were categorized as mature eggs (red arrow).
\end{abstract}

Author Contributions: Conceptualization, C.F. and F.B.; methodology, C.F., C.P., F.B. and P.M.; formal analysis, C.P., M.M. and P.M.; writing-original draft preparation, C.F. and F.B.; writing-review and editing, C.F., C.P., F.B., M.M., P.M. and S.B.; supervision, C.F.; funding acquisition, C.F., F.B. and S.B. All authors have read and agreed to the published version of the manuscript.

Funding: This research was funded by Regione Piemonte, ALCOTRA 2014-2020 PITEM BIODIVALP.

Institutional Review Board Statement: All the insect rearings and experiments were conducted in accordance with the legislation and guidelines of the European Union for the protection of animals used for scientific purposes (http:/ / ec.europa.eu/environment/chemicals/lab_animals/legislation_ en.htm, accessed on 30 November 2021). All experimental protocols using insects were approved by the ad hoc Committee of DISAFA of the University of Torino.

Informed Consent Statement: Not applicable.

Data Availability Statement: Not applicable.

Acknowledgments: The authors would like to thank Regione Piemonte, Ente di gestione delle aree protette delle Alpi Cozie, Parco Naturale Alpi Marittime, Matteo Massara, Bruno Gallino, Paolo Varese, and Giorgio Gentile for their support in the field activities. The authors would like to thank the anonymous reviewers for their valuable comments and suggestions which improved the quality of the paper.

Conflicts of Interest: The authors declare no conflict of interest.

\title{
References
}

1. Guarrasi, M.A. Potential Impacts and Control of the Non Native Box Tree Moth in Canada. Frans Eggermont. 2018. Available online: https:/ / www.cif-ifc.org/wp-content/uploads/2019/10/2019ConfPres_S05P2_Potential-Impacts-and-Managementof-theNon-Native-Box-Tree-Moth-in-Canada-_Mariaelana-A-Guarrasi.pdf (accessed on 3 December 2020).

2. EPPO. Mini Data Sheet on Cydalima (=Diaphania). Available online: https://gd.eppo.int/download/doc/1064_minids_ DPHNPE.pdf (accessed on 21 December 2021).

3. CABI Cydalima perspectalis (Box Tree Moth). Available online: http://www.cabi.org/isc/datasheet/118433 (accessed on 21 December 2021).

4. FEI (Forum Entomologi Italiani). Cydalima perspectalis (Walker, 1859)-Crambidae-Vicenza. Available online: http://www. entomologiitaliani.net/public/forum/phpBB3/viewtopic.php?t=12721 (accessed on 29 October 2021).

5. Bella, S. The box tree moth Cydalima perspectalis (Walker, 1859) continues to spread in southern Europe: New records for Italy (Lepidoptera Pyraloidea Crambidae). Redia 2013, 96, 51-55.

6. Raineri, V.; Bonechi, F.; Caracciolo, D.; Cresta, P.; Mariotti, M. Cydalima perspectalis (Walker, 1859) (Lepidoptera, Crambidae) and the threats for the Nature 2000 Habitat 5110 in Liguria (NW-Italy). BMIB-Boll. dei Musei e Degli Ist. Biol. 2017, 79, 215-236.

7. Raviglione, M.C.; Boggio, F.; Buttè, F. Prima segnalazione di Cydalima perspectalis (Walker, 1859) in Piemonte (Lepidoptera Crambidae). Riv. Piemont. Di Stor. Nat. 2013, 34, 159-170.

8. Wan, H.; Haye, T.; Kenis, M.; Nacambo, S.; Xu, H.; Zhang, F.; Li, H. Biology and natural enemies of Cydalima perspectalis in Asia: Is there biological control potential in Europe? J. Appl. Entomol. 2014, 138, 715-722. [CrossRef]

9. Nacambo, S.; Leuthardt, F.L.G.; Wan, H.; Li, H.; Haye, T.; Baur, B.; Weiss, R.M.; Kenis, M. Development characteristics of the box-tree moth Cydalima perspectalis and its potential distribution in Europe. J. Appl. Entomol. 2014, 138, 14-26. [CrossRef]

10. Leuthardt, F.L.G.; Glauser, G.; Baur, B. Composition of alkaloids in different box tree varieties and their uptake by the box tree moth Cydalima perspectalis. Chem. Ecol. 2013, 23, 203-212. [CrossRef]

11. Van der Straten, M.J.; Muus, T.S.T. The box tree pyralid, Glyphodes perspectalis (Lepidoptera: Crambidae), an invasive alien moth ruining box trees. Proc. Neth. Entomol. Soc. Meet. 2010, 21, 107-111.

12. Korycinska, A.; Eyre, D. Box Tree Caterpillar, Diaphania Perspectalis; The Food and Environment Research Agency (FERA): York, UK, 2009; p. 4. Available online: http://www.fera.dfra.gov.uk/plants/plantHealth/pestsDiseases/documents/boxTreeCaterpillar. pdf (accessed on 21 December 2021).

13. Wang, J.M. The biological character and control of a new pest (Diaphania perspectalis) on Murraya paniculata. J. Fujian For. Sci. Technol. 2008, 4, 161-164. 
14. Di Domenico, F.; Lucchese, F.; Magri, D. Buxus in Europe: Late Quaternary dynamics and modern vulnerability. Perspect Plant Ecol. 2012, 14, 354-362. [CrossRef]

15. Kenis, M.; Nacambo, S.; Leuthardt, F.L.G.; Domenico, F.D.; Haye, T. The box tree moth, Cydalima perspectalis, in Europe: Horticultural pest or environmental disaster? Aliens 2013, 33, 38-41.

16. ETC/BD. Article 17 Reporting-Assessments of Conservation Status at the EU Biogeographical Level-Public Consultation. ETC/BD Technical Paper 3/2014. Paris, France. Available online: https://www.eionet.europa.eu/etcs/etc-bd/products/etc-bdreports/art17rp2_cs_at_eu_level (accessed on 30 November 2021).

17. Picciau, L.; Ferracini, C.; Alma, A. Reproductive traits in Torymus sinensis, biocontrol agent of the Asian chestnut gall wasp: Implications for biological control success. Bull. Insectol. 2017, 70, 49-55.

18. Picciau, L.; Alma, A.; Ferracini, C. Effect of different feeding sources on lifespan and fecundity in the biocontrol agent Torymus sinensis. Biol. Control 2019, 134, 45-52. [CrossRef]

19. Jervis, M.A.; Heimpel, G.E.; Ferns, P.N.; Harvey, J.A.; Kidd, N.A.C. Life-History Strategies in Parasitoid Wasps: A Comparative Analysis of 'Ovigeny'. J. Anim. Ecol. 2001, 70, 442-458. [CrossRef]

20. Santi, F.; Radeghieri, P.; Sigurta, G.; Maini, S. Sex pheromone traps for detection of the invasive box tree moth in Italy. Bull. Insectol. 2015, 68, 158-160.

21. Bakay, L.; Kollár, J. The spread rate of Cydalima perspectalis (Walker 1859) in Slovakia (2013-2015). In Plants in Urban Areas and Landscape; Rovná, K., Kollár, J., Eds.; Slovak University of Agriculture in Nitra: Nitra, Slovakia, 2018; pp. 51-54.

22. Elisovetskaya, D.; Calestru, L.; Ţugulea, H.C.; Derjanschi, V. Biological peculiarities of Cydalima perspectalis (Walker, 1859) in the conditions of the Republic of Moldova. Agrofor. Int. J. 2020, 5, 88-99.

23. Park, I. Ecological characteristics of Glyphodes perspectalis. Korean J. Appl. Entomol. 2008, 47, 299-301. [CrossRef]

24. Karpun, N.N.; Ignatova, Y.A. The First Report about Cydalima perspectalis Walker on the Black Sea Coast of Russia; The State Research Institution All-Russian Scientific and Research Institute of Floriculture and Subtropical Crops of the Russian Academy of Agricultural Sciences: Sochi, Russia, 2013; Available online: www.rusnauka.com/31_NNM_2013/Biologia/7_146134.doc.htm (accessed on 21 December 2021).

25. Göttig, S.; Herz, A. Observations on the seasonal flight activity of the box tree pyralid Cydalima perspectalis (Lepidoptera: Crambidae) in the Rhine-Main Region of Hessia. J. Cultiv. Plants 2017, 69, 157-165.

26. Kulfan, J.; Zach, P.; Holec, J.; Brown, P.M.J.; Sarvašová, L.; Skuhrovec, J.; Martinková, Z.; Honěk, A.; Vál'ka, J.; Holecová, M.; et al The invasive box tree moth five years after introduction in Slovakia: Damage risk to box trees in urban habitats. Forests 2020, 11, 999. [CrossRef]

27. Badano, D.; Caracciolo, D.; Mariotti, M.; Raineri, V. Destruction of a protected habitat by an invasive alien species: The case of Cydalima perspectalis (Walker, 1859) in the box tree formations of Liguria (North-West Italy) (Lepidoptera: Crambidae). SHILAP Rev. De Lepidopterol. 2019, 47, 87-95.

28. Suppo, C.; Bras, A.; Robinet, C. A temperature-and photoperiod-driven model reveals complex temporal population dynamics of the invasive box tree moth in Europe. Ecol. Model. 2020, 432, 109229. [CrossRef]

29. Byrne, D.; Von Bretzel, P.K.; Hoffman, C.J. Impact of Trap Design and Placement When Monitoring for the Bandedwinged Whitefly and the Sweetpotato Whitefly (Homoptera: Aleyrodidae). Environ. Entomol. 1986, 15, 300-304. [CrossRef]

30. Whitfield, E.C.; Lobos, E.; Cork, A.; Hall, D.R. Comparison of different trap designs for capture of noctuid moths (Lepidoptera: Noctuidae) with pheromone and floral odor attractants. J. Econ. Entomol. 2019, 112, 2199-2206. [CrossRef] [PubMed]

31. Kawazu, K.; Honda, H.; Nakamura, S.; Adati, T. Identification of sex pheromone components of the box tree pyralid, Glyphodes perspectalis. J. Chem. Ecol. 2007, 33, 1978-1985. [CrossRef] [PubMed]

32. Kim, J.; Park, I.K. Female sex pheromone components of the box tree pyralid, Glyphodes perspectalis, in Korea: Field test and development of film-type lure. J. Asia Pac. Entomol. 2013, 16, 473-477. [CrossRef]

33. Aghdam, H.R. Are pheromone traps applicable to forecast an insect pest phenology? A case study on codling moth. Crop Prot. 2015, 4, 121-130. [CrossRef]

34. Ferracini, C.; Pogolotti, C.; Lentini, G.; Saitta, V.; Busato, E.; Rama, F.; Alma, A. Performance of Pheromone-Baited Traps to Monitor the Seasonal Abundance of Tortrix Moths in Chestnut Groves. Insects 2021, 11, 807. [CrossRef]

35. Molnár, B.P.; Kárpáti, Z.; Nagy, A.; Szarukán, I.; Csabai, J.; Koczor, S.; Tóth, M. Development of a female-targeted lure for the box tree moth Cydalima perspectalis (Lepidoptera: Crambidae): A preliminary report. J. Chem. Ecol. 2019, 45, 657-666. [CrossRef]

36. Poitou, L.; Bras, A.; Pineau, P.; Lorme, P.; Roques, A.; Rousselet, J.; Laparie, M. Diapause regulation in newly invaded environments: Termination timing allows matching novel climatic constraints in the box tree moth, Cydalima perspectalis (Lepidoptera: Crambidae). Insects 2020, 11, 629. [CrossRef]

37. Pollard, C.P.; Griffin, C.T.; de Andrade Moral, R.; Duffy, C.; Chuche, J.; Gaffney, M.T.; Fealy, R.M.; Fealy, R. phenModel: A temperature-dependent phenology/voltinism model for a herbivorous insect incorporating facultative diapause and budburst. Ecol. Model. 2020, 416, 108910. [CrossRef]

38. Xiao, H.J.; Xin, H.Q.; Zhu, X.F.; Xue, F.S. Photoperiod and temperature of diapause induction in Diaphania perspectalis (Lepidoptera: Pyralidae). Chin. J. Appl. Entomol. 2011, 48, 116-120.

39. Kearney, M.; Porter, W. Mechanistic niche modelling: Combining physiological and spatial data to predict species' ranges. Ecol. Lett. 2009, 12, 334-350. [CrossRef] [PubMed] 
40. Pincebourde, S.; Murdock, C.C.; Vickers, M.; Sears, M.W. Fine-scale microclimatic variation can shape the responses of organisms to global change in both natural and urban environments. Integr. Comp. Biol. 2016, 56, 45-61. [CrossRef] [PubMed]

41. Martini, A.; Di Vitantonio, C.; Dindo, M.L. Acceptance and suitability of the box tree moth Cydalima perspectalis as host for the tachinid parasitoid Exorista larvarum. Bull. Insectol. 2019, 72, 150-160.

42. Martini, A.; Di Vitantonio, C.; Ferracini, C.; Dindo, M.L. Interactions between the box tree moth Cydalima perspectalis (Walker) and the tachinid parasitoid Exorista larvarum (L.). In Proceedings of the 6th International Entomophagous Insects Conference, Perugia, Italy, 9-13 September 2019; p. 108.

43. Rose, J.; Kleespies, R.G.; Wang, Y.; Wennmann, J.T.; Jehle, J.A. On the susceptibility of the box tree moth Cydalima perspectalis to Anagrapha falcifera nucleopolyhedrovirus (AnfaNPV). J. Invertebr. Pathol. 2013, 113, 191-197. [CrossRef]

44. Göttig, S.; Korn, S.; Herz, A. Repellent and toxic properties of plant oils and extracts on Cydalima perspectalis Walker (Lepidoptera: Crambidae). Arch. Phytopathol. Plant Prot. 2017, 50, 658-673. [CrossRef]

45. Szelényi, M.O.; Erdei, A.L.; Jósvai, J.K.; Radványi, D.; Sümegi, B.; Vétek, G.; Molnár, B.P.; Kárpáti, Z. Essential oil headspace volatiles prevent invasive box tree moth (Cydalima perspectalis) oviposition-insights from electrophysiology and behaviour. Insects 2020, 11, 465. [CrossRef]

46. Gokturk, T.; Chachkhiani-Anasashvili, N.; Kordali, S.; Dumbadze, G.; Bozhuyuk, A.U. Insecticidal effects of some essential oils against box tree moth (Cydalima perspectalis Walker (Lepidoptera: Crambidae)). Int. J. Trop. Insect Sci. 2020, 41, 313-322. [CrossRef]

47. John, R.; Schumacher, J. Der Buchsbaum-Zünsler (Cydalima perspectalis) im Grenzach-Wyhlener Buchswald-Invasionschronik und Monitoringergebnisse Reinhold. Gesunde Pflanz. 2013, 65, 1-6. [CrossRef]

48. Plant, C.W.; Poole, C.; Salisbury, A.; Bird, D. The box-tree moth Cydalima perspectalis (Walker, 1859) in Britain: An overview of its spread and current status. Entomol. Rec. J. Var. 2019, 131, 122-147.

49. Dlugosch, K.M.; Parker, I.M. Founding events in species invasions: Genetic variation, adaptive evolution, and the role of multiple introductions. Mol. Ecol. 2008, 17, 431-449. [CrossRef]

50. Seiter, S.; Kingsolver, J. Environmental determinants of population divergence in life-history traits for an invasive species: Climate, seasonality and natural enemies. J. Evol. Biol. 2013, 26, 1634-1645. [CrossRef] [PubMed]

51. Donohue, K.; Pyle, E.H.; Messiqua, D.; Heschel, M.S.; Schmitt, J. Adaptive divergence in plasticity in natural populations of Impatiens capensis and its consequences for performance in novel habitats. Evol. Int. J. Org. Evol. 2001, 55, 692-702. [CrossRef]

52. Richards, C.L.; Bossdorf, O.; Muth, N.Z.; Guerevitch, J.; Pigliucci, M. Review and Jack of all trades, master of some: On the role of phenotypic plasticity in plant invasions. Ecol. Lett. 2006, 9, 981-993. [CrossRef] [PubMed]

53. Yeh, P.J.; Price, T.D. Adaptive phenotypic plasticity and the successful colonization of a novel environment. Am. Nat. 2011, 164, 531-542. [CrossRef] [PubMed]

54. Quacchia, A.; Ferracini, C.; Bonelli, S.; Balletto, E.; Alma, A. Can the Geranium Bronze, Cacyreus marshalli, become a threat for European biodiversity? Biodiv. Conserv. 2008, 17, 1429-1437. [CrossRef]

55. Branco, M.; Brockerhoff, E.G.; Castagneyrol, B.; Orazio, C.; Jactel, H. Host Range Expansion of Native Insects to Exotic Trees Increases with Area of Introduction and the Presence of Congeneric Native Trees. J. Appl. Ecol. 2015, 52, 69-77. [CrossRef]

56. Hardy, N.B.; Peterson, D.A.; Normark, B.B. Scale insect host ranges are broader in the tropics. Biol. Lett. 2015, 11, 20150924. [CrossRef]

57. Nacambo, S. Parasitisme, Développement, Modèle Climatique et Impact de Cydalima perspectalis en Europe. Master's Thesis, University of Neuchâtel, Neuchâtel, Switzerland, 2012.

58. Göttig, S.; Herz, A. Are egg parasitoids of the genus Trichogramma (Hymenoptera: Trichogrammatidae) promising biological control agents for regulating the invasive Box tree pyralid, Cydalima perspectalis (Lepidoptera: Crambidae)? Biocontrol. Sci. Technol. 2016, 26, 1471-1488. [CrossRef]

59. Albert, R.; Lehneis, T. Der Buchsbaumzunzler, ein neuer Problemschadling in Baden-Wurttemberg. Land 2010, 3, 40-45. (In German)

60. Göttig, S. Development of Eco-Friendly Methods for Monitoring and Regulating the Box Tree Pyralid, Cydalima perspectalis (Lepidoptera: Crambidae), an Invasive Pest in Ornamentals. Ph.D. Thesis, Technische Universität, Darmstadt, Germany, 2017. 